\title{
PARA O LEITOR LER DE/VAGAR HERBERTO HELDER
}

\section{Maria Lúcia Dal Farra. •}

Como um signo digital do código de sinalização que zela a entrada para o seu universo, o poema "Para o leitor ler de/vagar", de Herberto Helder, 1 planteia o "modus". Já o título em forma de apelo imediatamente conativo, já nos próprios recursos internos que, através da pontuação, regulam o ritmo.

O andamento "de/vagar", controlado pelo título, não é um procedimento que se possa evitar, desde que a exigência se interioriza no corpo do poema, torna-se uma auto-determinaçāo que se estende ao leitor e lhe rege os passos. Resta a este, introduzir-se no veículo - o poema - cujo sistema sutil de engrenagens e freios permite uma viagem atenciosa, num ritmo ditado pela própria organização plurivalente das peças, dispostas em frases menores ou maiores. Alçapão aberto, elas regulam a redução ou intensificação da marcha.

O leitor se encontra, assim, no domínio do tempo: o tempo dú poema, o tempo para ler o poema, o tempo de ler o poema, o tempo que passa sobre o poema. Que jogos escusos entre diacronia e sincronia o poema dilata na sua combustão semåntica?

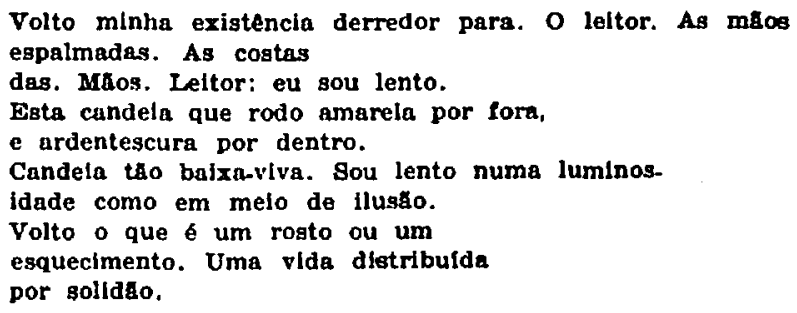

* Mestre $(O$ discurio a procura do discurso: estudo dos romances de primelra pessoa de Virgilio Ferreira, Universidade de Sto Paulo, 1973), Maria Lucla Dal Farra já publicou aua tese (Sao Paulo, 1979), Virgillo Ferreira - as duas faces do Mythos (Colbquio/Letras, no 22), Úmberto Eco, as for. mas do conteúdo (Dlscarsos no 5, USP, Săo Paulo). Atualmente, bolsiata da Fundaçăo de Amparo a Pesquisa prepara a gua tese de Doutoramento.

1 HELDER, Herberto. Para o leitor ler de/vagar. In: - Poesla toda. Llsboa, Plátano, 1973. p. 148-61. 
FARRA. M. L. Paro o leitor ler de/ragar Herberto Heider

Sou Pechado

como uma nedra pedrissima. Perdidiasima

da boca transacta. Fechado

como uma. Pedra sem orelhas. Pedra una

reduzida a. Pedra.

Pedra sem rálrulas. Com a cor reduzlda

u. Um dia de louvor. Proferida lenta.

Escutada lenta.

- Todo o leitor é de safira. é

de. Turquesa.

E a vida executada. Deragar.

Torna-so a inflitrada cor da. Pedra

do leltor.

Volto parn esosa pedra absoluta. Relatira

a minha pedra.

Minhu pedira pensada com a lorma

de. Uma lenta vida elementar.

Leitor acentuado, redobrado leitor moroso.

Quen entende o relato sem poros,

o mes atron dealbado sobre a pedra

sem orelhas, pedra sem boca. E que desce os dedos

Sobre. Meus dedos pelo ar. E toca e pasea.

Pelas pálpebras parndas. Pelos

cerrados lábios até às ralzes.

E cal com seus dedos em meus dedos.

Podres. E espera devagar.

Leitor que espera uma flor atravancada.

baloucando baira

sobre. Mergulhadas

fllamentos no terror

devagar.

Mas que espera. Doce. Contra o hermético

movimento do mundo.

$F$ que o mundo movimenta contra.

As ondas de Deus auxiliado

auxillar. E que Deus morimenta contra. Suas ondas

multo lentas, amarguradas ondas muito.

Antigas, Ignoradas, corridas. Sobre

a primitiva face do poema. Leitor

que sabers o que sabe dentro. Do que sabe

de mals selado. E esperara

dlas e anos dobrado, leitor. Varrido

pelo morimento dos dias.

Contra o movimento nocturno do. Poema devagar.

$E$ que espera.

E para quem rolto. Muitas coisas sobre

uma coisa. Volto

uma exaltante morte de Deus. Aurillado

auxillar. $O$ espirito. a pedra.

Do poema.

Leitor a minha frente. Vindo

do mais diffcil lado

das noites. Ainda tocado e molhado 
de suas flores aniquiladas.

Rodo. Parn esse rosto difuso e ragaroso meu sono.

A fantasia minucioss, A obliqua inovacáo.

A solidåo. Trémula devagar.

Leitor: volto

para tl. Um livro que val morrer depressa.

Depressa antes. Que a onda venha, a onda

alague. A noite cafda em clma de teug dedos.

De encontro a cor de encontro a. Paragem

da cor. Este livro apertado nas estrelas

da boca, estrelas.

Aderentes fechadas. Por fora

leves as rezes, presas.

Para eu batelas durante o tempo.

Eterno, o tempo. De uma onda maior que o nosso

tempo. O tempo leltor de um. Autor.

Ou um livro e um Deus com ondas de um mar

mals pacientes.

Ondas do que um leitor devagar.

Devagar. De/vagar.

O título pede precaução. Indica: "vá com atenção!", "siga lentamente!", "demore-se no tempo!". Caminhando vagarosamente pelo signo "de/vagar", o leitor se vê arremessado, de imediato, a outra acepção: a pausa irregular que separa o vocábulo sugere, além de andamento. uma condiçăo - "à maneira de vagar". Vagar. Andar sem destino e vaguear, ou estar vazio e sem propriedade?

Se, como se verá, o leitor é guiado e crlado pela própria leitura impressa no poema, a polifonia do título vem excluir a hipótese de uma leitura em vaguear, de uma leitura sem destino.

"A maneira de estar vazio" indica que o poema espera ser preenchido e aponta para o elemento complementar de tempo - o espaço. As oraçōes, construídas à maneira de transitividade interrompida e pontuadas por notações de andamento, geram, por isso. um lugar aberto.

O poema contém um espaço sem propriedade - aquele em que cabe o leitor - e que espera o momento de ser apropriado. As pausas conferidas pelo devagar temporal asseguram o preenchimento do de/vagar espacial. O leitor, enquanto criação do poema, não pode se evadir nem de um ou outro limite: ambos contêm o seu debater. Seu molde está esboçado, e basta somente que, pelo procedimento temporal, ele se introduza.

Deste modo, a atitude critica imposta pelo poema deve consistir na observação das duas acepçōes de "devagar": "devagar" enquanto atença!, "de/vagar" enquanto preenchimento do vazio.

"Para o leitor ler de/vagar" se constrói, assim, nos intercâmbios da tensão entre espaço e tempo do leitor e do poema. Sua preocupação constante é a da competência linguística do poema em relação 
ao leitor e do leitor em relaçāo ao poema, enfocando a questāo do desgaste ou enriquecimento temporal.

Como adequar as camadas significativas inseridas no seu corpo, temporal e transitório, mas coagulado no gesto de escrita, à excessiva contingência do leitor? Como adequar o seu perpétuo estado de mudez. cegueira e surdez à receptividade do destinatário? Daquele que "esperará / dias e anos dobrado, leitor. Varrido / pelo movimento dos dias. / Contra o movimento noctumo do. Poema devagar"? Como controlar o "tempo leitor de um. Autor"?

Contra o "devagar" do poema, caminha o "depressa" do tempo no seu ofício de resgate ou de recobrimento semântico. E a preservação que Helder busca para a sua poesia é encontrada, aqui, na execução de um egoísmo poemático exemplar.

O poema-emissor circunda-se: ele se volta, ele se roda. ele constrói um movimento em órbita de si mesmo. Sua atenção está situada sobre sua própria esfera de ação, e não se estranha que esteja incluída nela a presença do leitor. Na formação dos pontos discretos que atestam a existência do proferidor, delineia-se a do leitor: não a do passageiro fortuito ou a do convidado eventual, mas a daquele que o poema gera. fixando permanentemente nos seus espaços.

Neste ato de parir-se - já que inicia o leitor na arte de sun compreensão, a fim de que, formando-o. forme-se a si mesmo - o poema, revestido de um solipsismo exacerbado, porque se quer compreendido (e qual a melhor maneira de ser apreendido senão a de ensinar a própria aprendizagem?). fala somente de si.

Sua conformaçāo decorre da necessidade de incorporar-se ao leitor, de tornar as duas pedras uma, e procedendo assim ele se apoia no centro e traça à sua volta o círculo das declarações.

Uma linha continua de lealdade e até mesmo de despudor percorre o texto em busca dos seus conceitos. O poema se defina (1.: 2.: e 3." estrofe), o poema define o leitor em relação a si (4:" e $5^{\circ}$ estrofes), o poema define o impacto entre poema e leitor (6.* e 7.2 estrofes), e define, por fim, as possibilidades de leitura sobre si mesmo (8." estrofe).

Entretanto, a maneira de se conceituar e de se ensinar ao leitor não é imediata nem literal. Ela é mediatizada pelo ato de o poema ser a corporificação simultánea da teoria que nomeia. Por intermédio da própria coesão fntima dos signos que o compōem - através das suas leis de contiguidade e de equivalência - o poema articula os conceitos ao mesmo tempo em que se executa refletindo-os. Ele se define sendo a definiçāo. Ele se ensina somente porque realiza no flagrante da emissão poética a sua didática.

Desta forma. o que ele diz que é, é o que ele é dizendo, pois que ele se torna. sem distáncia temporal, sujeito e objeto da sua própria enunciação. 


\section{O poema se define}

Contrariamente à tradição poética hermética e esotérica que conserva o poema em cstado de enigma, o poema se define sem segredos, de māos abertas, expondo o verso e o reverso da sua limpeza e sinceridade. As duas declaraçōes de princípios - "sou lento", "sou fechado" - o intensificam e dão voz ao símbolo de "As mãos / espalmadas. As costas / das. Mãos".

A esta declaração se adiciona a da "candeia", também rodada e circundada a fim de conferir luz à exploraçāo do limite circular. Toda a busca se faz sempre na mesma direção, à procura do próprio espaço de esfera (de espera?) que é o poema.

A luz enquanto emblema poético - o espelho, a lâmpada - remete respectivamente à poesia mimética e nāo mimética. Se a lâmpada fala da subjetividade criadora e do auto-conhecimento de uma consciência - e do "eu" poético - a pequena lâmpada contida na "candeia" do poema revela dois lados: seu âmbito perceptual e conceptual que, neste universo onde crítico e leitor são integrados num único corpo - num único texto - estāo enredados.

Se a "candeia" ilumina "amarela" por fora (e eis o correspondente colorido para o signo digital de "devagar"), ela tem a funçāo de comunicar seu próprio conhecimento crítico, dirigir os passos do leitor em direção ao seu interior, ainda que reconheça no matiz da cor o pressentimento da obscuridade do poema. Entretanto, o conhecimento que "candeia" e poema iluminam não é o do "eu" poético e subjetivo, mas aquele do próprio poema, que se faz e se investiga.

Iluminando por dentro - e esta é sua atitude conceptual e teórica - ele se confessa vivamente escuro. Nada se oculta do leitor. nem mesmo a obscuridade interior. Tanto é assim que a explicitação dos dois lados confundidos e integrados é feita de imediato através de um único vocábulo resultante do traço de uniāo: "tão baixa-viva"

A lentidão de que o poema falava é transparecida numa "luminosidade" que implica ao mesmo tempo "candeia" e "de/vagar". O atributo "luminosidade" se prolifera em duas direçōes: luminosa e idade A realização verbal da "luminos-idade" é complementária da lentidã.s pelo texto e aceita pelo leitor: o leitor se encontra diante da postura sincera e anti-enganosa do póema que não se poupa, advertindo pela conformação verbal do seu estado "em meio de ilusão", do seu estado passível de engano dos sentidos ou da inteligência. passível de ser erroneamente interpretado.

Também inserida na "luminos-idade" encontra-se a preocupação temporal, pois o poema supōe, já agora o trabalho da diacronia, o perigo das diferentes manipulaçōes no decorrer do tempo. Pedra fechada, sua cor está "reduzida a. Um dia de louvor", à apreciação. Perdido da "boca transacta". ele está imóvel, O poema já não fala. nāo ouve, não pode rearranjar-se: a boca que o proferiu, aquela que 
articulou-lhe as combinações semânticas e rítmicas, já é pretérita. "Pedra sem válvulas", suas explosōes se fazem dentro. Não há outro emissor que nāo ele próprio, e é por isso que. durante todo o tempo, ele procura dirigir a leitura, formar o seu leitor, ainda que o inquietem as dúvidas acerca dos diferentes intercâmbios temporais.

\section{O poema define o leitor em relaçăo a 81}

Sujeito à avaliação, o poema se dirige ao leitor: à pedra safira. à pedra turquesa. O primeiro pode ter conhecimento crítico verdadeiro, o segundo, entretanto, pode parecer ter. De qualquer forma. esta pedra "absoluta" é sempre "relativa" a sua pedra, e é por esta razāo que, na última estrofe, o poema abrirá em plurissignificação o seu corpo. O poema pensando através de uma vida "elementar" ou através de algo que diga respeito aos princípios da poética?

Há o leitor "acentuado, redobrado leitor moroso" e há o leitor "que cspera uma flor atravancada". Ambos esperam, ambos caminham "de / vagar" pelo poema e pelo tempo. O primeiro é capaz de por em relevo aquilo que o pocma pede, é capaz de entender o movimento do tempo em relação à imobilidade do poema ("o mês dealbado sobre a pedra sem orelhas, pedra sem boca"). de entender as relaçōes ("o relato") e de identificar-se com ele na própria decomposiçāo do poema ("cai com os seus dedos em meus dedos. Podres"). O outrn imagina encontrar embaraços por baixo da textura dos signos.

\section{O poema define o impacto sobre poema e leitor}

A movimentação interior do poema, sua combustão, suas explosōes dentro, o seu âmago de "pedra sem válvulas", é desventrada e colocada em posição de adversidade para com o leitor.

Este movimento de oposição nāo se faz somente em relaçāo ao leitor, mas ocorre dentro do próprio corpo do poema: note-se a incidência de "contra" $\mathrm{e}$ as atribulaçōes rítmico-semânticas dal decorrentes. E nesta 6." estrofe que o intrincado sistema de circulação dos signos poéticos, seu fluxo, sua densidade e consisténcia, é sinceramente revelado. Toda uma cadeia semântica e sonora se estabclece para configurar e expelir a pele do poema, a sua "pedra" - a formação linguiistica e poética - e o seu "espírito", aquilo que habita seu universo.

No centro da dinàmica que torna o ativo em passivo e em seguida o passivo em ativo, num impulso contínuo de adversidade, en" contra-se a semente do processo executado e nomeado: o verbo "movimentar". Diante da abulição do poema, dos diferentes graus do processo de semiose que ele instaura, o leitor tem, agora, uma atitude estática: ele espera contra até que seu fluxo semântico convirja para o fluxo destilado dos semas e sememas do poema. 
0 ponto de pausa destas explosōes interiores é expresso pela "onda" que fornece o sentido perfeito para o apaziguamento das dife. rentes concorrências significativas: ela é o conjunto de pontos que, num meio em vibração. tem um movimento concordante.

o leitor espera contra o hermético movimento do mundo-poema, do mundo que movimienta contra as ondas de Deus auxiliado, auxiliar, de Deus que movimenta contra as ondas do leitor, muito lentas, amarguradas, ondas muito ignoradas, viajadas sobre a primitiva face do poema. Como numa cascata de signos de très tombos, o leitor espera, cmbaixo, que a movimentação aguda de semiose e simbioses interna; se acalme no encontro das suas ondas.

O mesmo movimento descendente estava inscrito quando do processo de identificação do leitor com o poema, quando ele descia as dedos, quando cáa, finalmente, com seus dedos nos dedos decompostos do poema.

Este mesmo "encontro" ressurgirá na última estrofe. Agora, elc se levanta em torno de arestas que se colocam por dentro do poema, que se expōem contra o leitor.

O universo do pocma ("o hermético movimento do mundo") se agita contra as ondas que compōem o mundo ("as ondas de Deus auxiliado auxiliar"), contra o Verbo, contra o próprio signo ao mesmo tempo passivo e ativo. O signo, poemático se movimenta contra a competência lingüística do leitor, desconhecida e enraizada, que sa havia articulado, antes, para nomear "a primeira face do poema". Os dois movimentos adversos se harmonizam, agora, no conflito do embate do latejar do poema com o do leitor. Somente depois do choque das vicissitudes de um e de outro é que será possível ao leitor ter conhecimento daquilo que tem sabor dentro do que tem sabor de mais selado. E assim. o egocentrismo do poema se exerce como instrumento de promoção da aprendizagem.

A preocupação temporal reaparece na nomeação do leitor que "esperará dias e anos dobrado", leitor "varrido pelo movimento dos dias". O noturno do poema contra o diurno do leitor. O devagar do poema (como decorrência diacrónica) contra o devagar do leitor (como diferentes decorrências sincrônicas). O poema fala dos leitores para os quais a ebulição do poema estará eclodindo à espera, pois, apesar de sua aparente imobilidade, ele traz em si o latejar incessante que resulta da contiguidade dos signos. Mesmo a morte deles - A "morte de Deus auxiliado, auxiliar" - é levada ao mais alto grau de energia: a contaminação semântica não cessa.

Porém, pesaroso $e$ inquieto, o poema volta para o leitor a sua solidão que, tremulando devagar, ainda conserva vibração - tal qual os signos, passivos e ativos, de que fala.

\section{0 poema define as possibllidades de leitura sobre sl mesmo}

Se o mesmo pode morrer antes da identificação, no seu casulo 
de pedra, na reclusāo de sua boca, ele se perpetuará num movimento incessante. Porque está na sua, a boca do leitor criado, e este, erigido pelos signos em contínua combustão, permitirá ao poema que ele se explore durante o tempo. Deste modo, seu destinatário não é mais o leitor, mas o tempo: o tempo leitor de um autor.

O poema está só, sem comunicação e recluso. Mas, graças ao "deus auxiliar" - os signos ativos em ebulição - e ao "deus auxiliado" o signo-leitor - ele permanece vivo e respira o seu próprio universo.

Reclamando vida para si, independentemente da possivel presença real de um leitor, o poema, na medida em que o concebe no seu corpo, torna-se auto-potente.

Se, entretanto, o leitor existe, o poema será plenamente realizado, e seu exercício decorrerá "do que o leitor devagar".

O procedimento "de/vagar" (tempo e espaço) tornado verbo, carrega toda a significaçāo de que se contaminou vagorosamente. Expressa, agora, a ação perfeita para o ato de decodificação do poema.

A preocupação da crítica diante dos problemas da criação poética enquanto procedimento mimético ou nāo. se transfere para o próprio objeto pesquisado. E o poema que, substituindo a investigação critica c teórica, toma para si o programa de estudos e o transforma no scu próprio corpo, sem sequer restringir sua natureza especifica.

O poema se volta para o seu âmago e procura investigá-lo na mcdida em que se exerce e se realiza como criaçāo artística. Esquecendo suas origens de representaçāo ou nāo da realidade, ele alcança a esfera crítica e sc situa num estágio de cogitaçāo conceptual, onda somente sua existência importa.

Zalando pela sua historicidade, ele se torna representação e concretizaçāo da teoria e da critica de que será passivel através do tempo. Ele se faz e se ensina. ele torna didático.

REFERENCIA BIBLIOGRAFICA

HELDER, Herberto. Poesla toda Ligboa, Plátano, 1973. v. 1

\section{Resumo}

O estudo "Para o leitor ler de/vagar" Herberto Helder" faz parte de um esforço mais amplo de compreensão da obra do poeta, onde se procura mostrar que uma das direções essenciais de sua poética é a de estabelecer um roteiro para uma possível leitura de si mesma.

A preocupação da crítica diante dos problemas da criação poética enquanto procedimento mimético ou nāo, se transfere, em Helder, pa ra o próprio objeto pesquisado. E o poema que, substituindo a investigação crítica e teórica, toma para si o programa de estudos e n transforma no seu próprio corpo, sem sequer restringir sua natureza específica.

0 poema se volta para o seu ámago e procura inevitavelmente investigá-lo, na medida em que se exerce e se realiza como criação 
artística. Esquecendo suas origens de representação ou nāo da realidade, ele alcança a esfera crítica e se situa num estágio de cogitaçāo conceptual, onde somente sua existência importa.

Zelando pela sua historicidade, ele se torna representação e concretização da teoria e crítica de que será possível através do tempo. Ele se faz c se ensina, ele se torna didático.

\section{Riassunto *}

Lo studio "Para o leitor ler de/vagar "Herberte Helder" fa parte di uno sforzo piú ampio di comprensione dell'opera del poeta in cui si cerca di mostrare che una delle direzioni essenziali della sua poetica è quella di stabilire un cammino per una sua possibile lettura.

La preoupazione della critica di fronte ai problemi della creazione poetica come procedimento mimetico o no, si trasferisce, in Helder, al proprio oggetto esaminato.

E il poema che, sostituendo l'investigazione critica e teorica, si appropria del programma di studi e lo trasforma nel suo próprio corpo, senza però restringere la sua natura specifica.

Il poema si volge alla sua essenza e cerca inevitabilmente d'investigarla man mano che si attua e realizza come creazione artistica. Dimenticando le sue origini di rappresentazione o no della realtà, esso raggiunge la sfera critica e si colloca in uno stadio di cogitazione concettuale in cui importa solamente la sua esistenza.

Zelando per la sua storicità, esso diventa rappresentazione e concrezione della teoria e critica delle quali sarà passibile con il transcorrere del tempo. Esso si fa, si insegna, diventa didattico.

* Versão da Professora Maria Carolina Massi Albanese. 